\title{
Gorceixita em Nefelina Sienitos do Stock Rio Pardo, Província Alcalina do Sul do Estado da Bahia, Nordeste do Brasil
}

Gorceixite in the nepheline syenite of the Rio Pardo Stock, South Bahia Alkaline Province, Northeast Brazil

\author{
H. Conceiçãa ${ }^{1 *}$; R. M. C. T. Figeiredo ${ }^{2}$; J. J. A. Santos ${ }^{1,3} ;$ M. L. S. Rosa ${ }^{1}$; \\ R. C. L. M. Oliveira ${ }^{4}$ \\ ${ }^{1}$ Programa de Pós-Graduação em Geociências e Análise de Bacias, Complexo Laboratorial Multiusuário da \\ Universidade Federal de Sergipe, Prédio das Geociências, 49100-000, São Cristóvão, Sergipe, Brasil \\ ${ }_{2}^{2}$ Iniciação Científica no Laboratório de Petrologia Aplicada à Pesquisa Mineral (LAPA-UFS) \\ ${ }^{3}$ Bolsita de Mestrado da Coordenação de Aperfeiçoamento do Pessoal do Nível Supeiror (CAPES) \\ ${ }^{4}$ Serviço Gelógico do Brasil (CPRM ) - SUREG/BA - Av. Ulysses Guimarães 2862, Centro Administrativo da Bahia, \\ 41213-000, Salvador-BA, Brasil
}

*herbet@ufs.br

(Recebido em 28 de dezembro de 2015; aceito em 29 de fevereiro de 2016)

\begin{abstract}
Identificou-se pela primeira vez a gorceixita $\left(\mathrm{BaAl}_{3}\left(\mathrm{PO}_{4}\right)\left(\mathrm{PO}_{3} \mathrm{OH}\right)(\mathrm{OH})_{6}\right)$ em nefelina sienitos do Stock Rio Pardo, na Província Alcalina do Sul do Estado da Bahia, que é um raro fosfato de bário aluminoso. Esse mineral ocorre, com tamanhos inferiores a $20 \mu \mathrm{m}$, na periferia ou em fraturas de cristais de flúor-apatita. As fraturas nos cristais de gorceixita são ocupadas por barita $\left(\mathrm{BaSO}_{4}\right)$ e monazita $\left[(\mathrm{Ce}, \mathrm{La}, \mathrm{Nd})\left(\mathrm{PO}_{4}\right)\right]$. Os contatos reentrantes entre os cristais de gorceixita e de flúor-apatita foram interpretados como devido à atuação de fluidos tardios, e a presença de barita e monazita indicam que as soluções de baixa temperatura que formaram a gorceixita foram igualmente responsáveis pela formação destes minerais.
\end{abstract}

Palavras-chave: Mineralogia, foid-sienitos, alteração

It was identified for the first time gorceixite $\left(\mathrm{BaAl}_{3}\left(\mathrm{PO}_{4}\right)\left(\mathrm{PO}_{3} \mathrm{OH}\right)(\mathrm{OH})_{6}\right)$ nepheline syenite in Stock Rio Pardo, in South Bahia Alkaline Province, which is a rare aluminous barium phosphate. This mineral occurs, with sizes below $20 \mu \mathrm{m}$, on the outskirts or fluoride - apatite crystals fractures. Fractures in gorceixita crystals are occupied by barite $\left(\mathrm{BaSO}_{4}\right)$ and monazite $\left[(\mathrm{Ce}, \mathrm{La}, \mathrm{Nd})\left(\mathrm{PO}_{4}\right)\right]$. The recessed contacts between the crystals and gorceixita fluorapatite was interpreted as due to delayed action of fluids and the presence of barite and monazite indicate that low-temperature solutions formed gorceixita were also responsible for the formation of these minerals.

Keywords: Mineralogy, foid syenites, alteration

\section{INTRODUÇÃO}

A gorceixita, $\mathrm{BaAl}_{3}\left(\mathrm{PO}_{4}\right)\left(\mathrm{PO}_{3} \mathrm{OH}\right)(\mathrm{OH})_{6}$, é um fosfato aluminoso de bário relativamente raro em rochas e descrito comumente em perfis de alteração de rochas alcalinas [1]. Cristais de gorceixita têm sido descritos: na diagênese de sedimentos marinhos [2]; em minérios lateríticos [3]; greisen com topázio [4]; em areias diamantíferas e alteração de carbonatitos [5, 6, 7, 8]; associados a carvão mineral [9]; e em pegmatitos [10, 11].

A gorceixita foi descrita pela primeira vez no Brasil em sedimentos arenosos, ao longo dos rios Abaeté, Bagagem e Douradinho na região de Diamantina (Minas Gerais) pelo francês Claude Henri Gorceix durante campanhas de prospecção para diamante, no extremo sul do Cráton de São Francisco [12]. O nome gorceixita foi dado por E. Hussak [13] a esse fosfato aluminoso de bário, em homenagem ao mineralogista francês Claude Henri Gorceix, que foi o primeiro diretor da Escola de Minas de Ouro Preto (1842 -1919). 


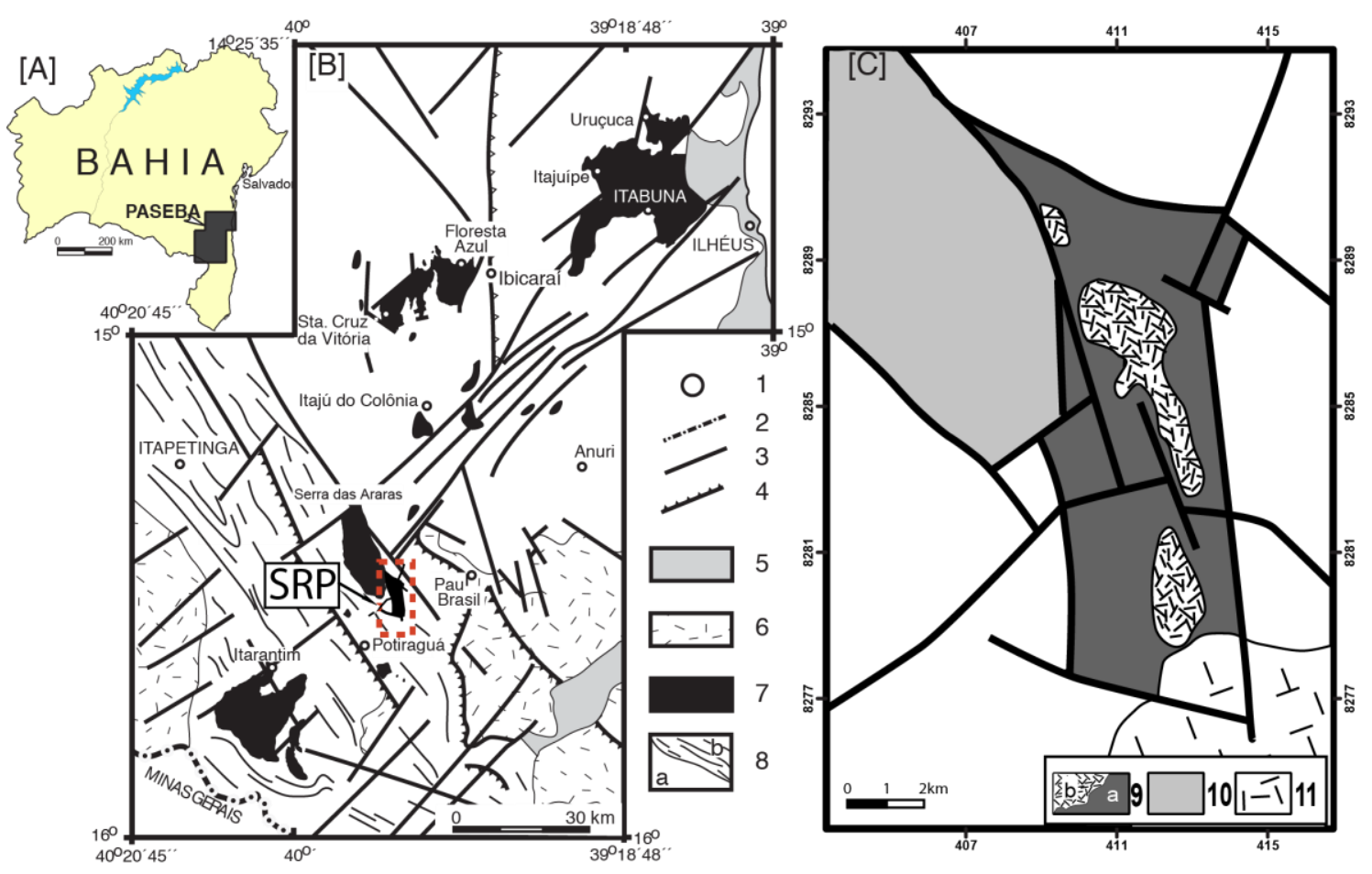

Figura 1. [A] Contorno geográfico da Estado da Bahia apresentando a área de abrangência da Província Alcalina do Sul do Estado da Bahia (PASEBA), em preto. [B] Esquema geológico da PASEBA [14]. [C] Esboço geológico do Stock Rio Pardo [15]. Cidades (1), limites estaduais (2), fraturas e falhas (3), falhas de cavalgamento (4), sedimentos recentes (5), metassedimentos da Bacia Rio Pardo (6), rochas alcalinas da PASEBA (7), embasamento arqueano-paleoproterozoico (8a $=$ gnaisse-migmatitos, $8 b=$ granulitos); Stock Rio Pardo ( $9 a=$ sodalita nefelina sienitos, $9 b=$ nefelina sienitos); Batólito Sienítico Serra das Araras (10), Complexo Gabro-Anortosítico (11).

Iniciamos em 2014 estudos detalhados da mineralogia acessória nos sienitos da Província Alcalina do Sul do Estado da Bahia (PASEBA, Figura 1A). Essa reavaliação está sendo feita com o auxílio da microscopia eletrônica de varredura, para identificar aqueles minerais acessórios com pequenos tamanhos $(<0,01 \mathrm{~mm})$, que não foram possíveis de serem identificados nos estudos petrológicos clássicos e que ocorrem nos nefelina sienitos, a rocha mais abundante nessa província alcalina. Como resultados desses estudos foi possível identificar pela primeira vez na PASEBA e igualmente no Estado da Bahia, os seguintes minerais: ancilita $\left[\mathrm{Sr}(\mathrm{Ce}, \mathrm{La})\left(\mathrm{CO}_{3}\right)_{2}(\mathrm{OH}) \cdot \mathrm{H}_{2} \mathrm{O}\right]$ [16], pirocloro $\left[(\mathrm{Ca}, \mathrm{Na}) \mathrm{Nb}_{2} \mathrm{O}_{6}(\mathrm{OH}, \mathrm{F})\right]$ [17] e zirconolita $\left(\mathrm{CaZrTi}_{2} \mathrm{O}_{7}\right)$ [18]. Nesse trabalho descreve-se a primeira ocorrência de gorceixita em sienitos do Stock Nefelina Sienítico de Rio Pardo (SRP), apresenta-se análises de químicas pontuais de cristais e discute-se as suas relações texturais com os cristais de apatita, monazita e barita com os quais ocorre associada.

\section{ASPECTOS GERAIS DO STOCK RIO PARDO}

O Stock Rio Pardo (SRP, $45 \mathrm{~km}^{2}$ ), com idade de $714 \pm 14 \mathrm{Ma}$ [13], se localiza na região sul da Bahia (Figura 1A), no município de Potiraguá, na parte centro-sul da PASEBA (Figura 1B). Ele é alongado NS, tendo seus contatos com o Batólito Sienítico Serra das Araras (739 \pm 2 Ma) [19], a oeste, e com o Complexo Gabro-Anortosítico Rio Pardo [20, 21] e os metamorfitos de alto grau do Orógeno Itabuna-Salvador-Curaçá, a leste (Figura 1C).

O SRP é essencialmente formado por álcali-sienito, álcali-sienito com nefelina, nefelina sienito, sodalita nefelina sienito e sodalita sienito e sodalititos, de granulação grossa a muito grossa. Estas rochas apresentam cores que variam de branco (álcali-sienito, álcali-sienito com 
nefelina), a esverdeada (nefelina sienitos), azulada (sodalita nefelina sienito, sodalita sienitos) e azul (sodalititos). Existem ainda no SRP domos e diques de fonólitos, diques de calcita carbonatitos e bolsões pegmatíticos alcalinos com nefelina e calcita [15].

Os dados geoquímicos do Stock Rio Pardo o posicionam no campo da evolução das suítes subsaturadas em $\mathrm{SiO}_{2}$ da PASEBA (Figura 2). Diversas amostras localizam-se nos campos do sienito e nefelina sienito e os termos mais diferenciados correspondem a sodalita sienitos e sodalititos. A evolução geoquímica apresentada por esse stock (Figura 2) é similar à encontrada em outros corpos dessa província [22, 23], ou seja, com a diferenciação ocorre a diminuição do $\mathrm{SiO}_{2}(63 \%$ a $45 \%$ ) e aumento dos conteúdos de $\mathrm{Na}_{2} \mathrm{O}$ (até $15 \%$ ), $\mathrm{Al}_{2} \mathrm{O}_{3}$ (até $25 \%$ ) e de cloreto (até $4 \%$ ). Esse comportamento foi interpretado [24] como resultante de contínuo fracionamento de clinopiroxênio, como descrito na literatura [25]. Os dados de isótopos de $\mathrm{Ce} \mathrm{O}$ obtidos em cristais de calcita intersticiais nesse stock apresentam assinatura isotópica mantélica [26], o que sugere que a cristalização fracionada desta intrusão ígnea se processou em ambiente geoquímico fechado.

Os valores elevados de alguns elementos traços como $\mathrm{Nb}$ (até $139 \mathrm{ppm}$ ), Y (até 41) e Zr (até 401 ppm) são característicos de rochas alcalinas anorogênicas o que é compatível com ambiente de rifte atribuído para a colocação da PASEBA no Criogeniano, quando da desfragmentação de Rodinia [14].

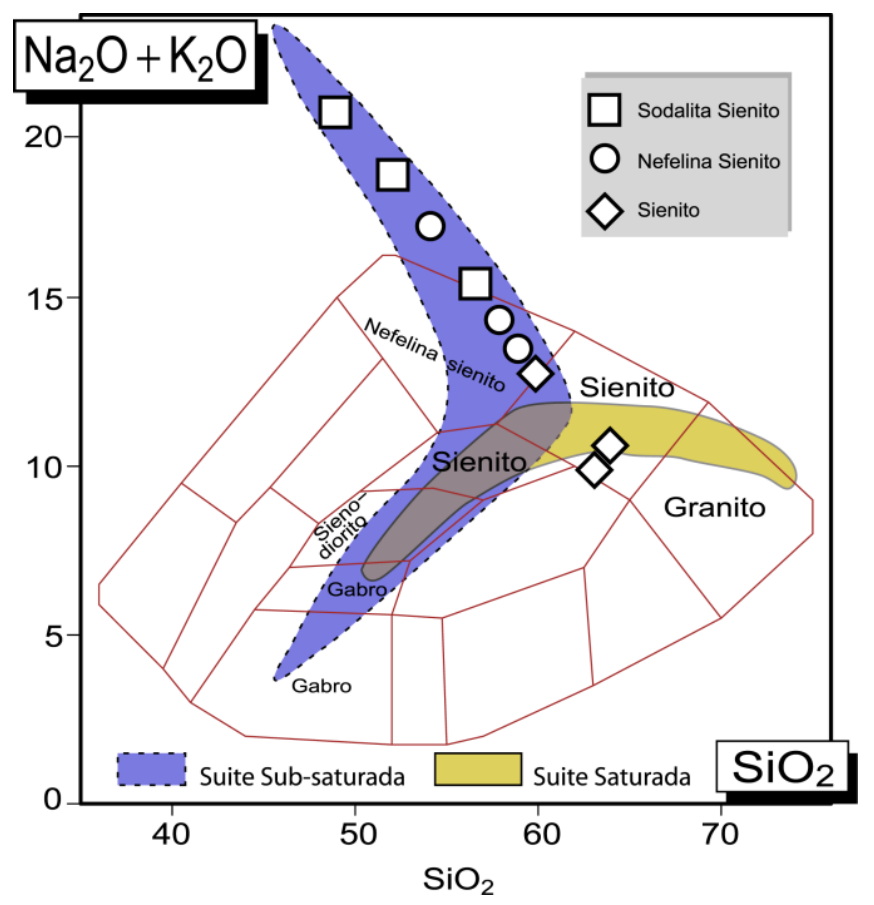

Figura 2. Diagrama Total de Álcalis $\left(\mathrm{Na}_{2} \mathrm{O}+\mathrm{K}_{2} \mathrm{O}\right)$ versus óxido de Silício $\left(\mathrm{SiO}_{2}\right)$ com campos de rochas plutônicas [27] aplicado às rochas da PASEBA. As duas tendências evolucionais geoquímicas presentes na PASEBA [14] são apresentadas: uma saturada e outra sub-saturada em óxido de silício. Disposição de amostras representativas do Stock Rio Pardo (sodalita sienito, nefelina sienito e sienito) aloca-se sobre a tendência evolucional sub-saturada em $\mathrm{SiO}_{2}$ desta província alcalina [15].

\section{MATERIAL E MÉTODOS}

A petrografia das rochas SRP foi realizada com o estudo de lâminas delgadas e de delgadopolidas de rochas representativas. Essas lâminas foram analisadas incialmente em microscópio 
petrográfico com luz transmitida e refletida e, posteriormente, por microscopia eletrônica de varredura.

Quando da análise petrográfica em luz transmitida dos nefelina sienitos da região sul do SRP identificou-se em um deles (Amostra PASEBA-2013) que os cristais de apatita, tanto naqueles inclusos em biotita quanto os dispersos na rocha, apresentavam-se coroados ou com fraturas preenchidas por um mineral incolor e com birrefringência um pouco mais baixa que a da apatita. Devido as suas dimensões $(<10 \mu \mathrm{m})$ o mineral das fraturas não pode ser identificado utilizandose da microscopia óptica.

A localização, descrição e análise dos cristais de gorceixita foram feitas utilizando-se de microscópio eletrônico de varredura (MEV), marca Tescan ${ }^{\circledR}$ (Vega 3), do Laboratório de Microanálises, do Condomínio de Laboratórios Multiusuários das Geociências (CLGeo), da Universidade Federal de Sergipe. Nesse equipamento têm-se acoplados detectores de elétrons secundários (SE), elétrons retroespalhados (BSE) e de catodoluminescência (CL) pantocromática com faixa espectral de $350-650 \mathrm{~nm}$.

A composição química pontual em cristais de gorceixita, apatita, monazita e barita foi obtida com equipando EDS (Energy Dispersive Spectroscopy) da marca Oxford Instrumentos ${ }^{\circledR}$, modelo $\mathrm{X}$-Act. As condições analíticas utilizadas nesse estudo foram: aceleração potencial de $15 \mathrm{Kv}$ e corrente variando de $10 \mathrm{nA}$ a $20 \mathrm{nA}$, o que gera um feixe de elétrons com diâmetro compreendido entre $290 \mathrm{~nm}$ a $830 \mathrm{~nm}$, o que permite análise de regiões muito pequenas nos cristais.

O EDS acoplando ao MEV do CLGeo tem detector SDD (Silicon Drift Detectors), com poder de resolução $125 \mathrm{eV}$. Com frequência utilizou-se esse espectrômetro para realizar mapas de elementos em regiões especificas da lâmina ou de cristais, como forma de identificar melhor os limites entre fases minerais presentes, o que facilitou em muito a seleção dos locais para a dosagem pontual da composição química dos cristais. Utilizou-se do software Quant ${ }^{\circledR}$, da Oxford Instrumentos $^{\circledR}$, para a determinação da composição química pontual dos cristais de forma automática. $\mathrm{O}$ tempo médio de contagem nessas dosagens variou entre 20 segundos e 60 segundos. Todavia, analisou-se individualmente os espectros de energia obtidos, com objetivo de eliminar-se os problemas da superposição de elementos [28]. Nesse contexto avaliou-se a presença de picos falsos, interferências de energia e a superposição de picos. Quando alguma destas situações ocorria eliminou-se manualmente essa interferência. A correção utilizada pelo software Quant ${ }^{\circledR}$ no tratamento dos dados químicos obtidos foi a ZAF. A precisão nos resultados dos elementos químicos varia com a concentração dos elementos dosados, sendo inferior a $2 \%$, para elementos com concentração superior a $20 \%$ em peso e de até $20 \%$ para elementos químicos com concentrações inferiores a $5 \%$ em peso.

\section{RESULTADOS E DISCUSSÃO}

Os nefelina sienitos estudados apresentam granulação média a grossa, texturas ígneas bem preservadas e marcadas por distribuição aleatória de cristais subédricos de feldspato alcalino pertítico, albita antipertítica e nefelina intersticial. Os cristais de annita encontram-se associados à ilmenita (com até $2 \%$ de $\mathrm{Nb}+\mathrm{Ta}$ ) e magnetita (com até $1 \%$ de V). Os minerais acessórios mais importantes são apatita e zircão, tendo sido identificados de forma subordinada cristais de pirocloro, baddeleyita, thorita e zirconolita. Alguns dos cristais de magnetita mostram-se total ou parcialmente alterados para uma mistura de óxidos e hidróxido de ferro os quais apresentam hábito botrioidal, indicando que localmente essas rochas foram submetidas a ação de fluidos de baixa temperaturas.

A presença de gorceixita foi encontrada apenas em um nefelina biotita álcali-sienito (PASEBA-2013) da região central do SRP. Essa rocha ao ser observada com lupa binocular não apresentou evidências visíveis de alteração. Todavia a presença de gorceixita, assim como a existência de alteração importante em cristais de magnetita, indica que fluidos de baixa temperatura atuaram nessa região do stock estudado.

Os cristais de gorceixita limitam-se a ocorrerem associados aos cristais de flúor-apatita. A gorceixita ocorre envolvendo os cristais de flúor-apatita ou dispondo-se em suas fraturas (Figura 
3). Essas feições texturais no SRP são coerentes com os relatos encontrados na literatura que descrevem a formação da gorceixita a partir da alteração em baixa temperatura de cristais de apatita $[3,5,6,7,8]$.

A gorceixita apresenta-se com fraturas menores e descontínuas que são preenchidas por monazita e barita (Figuras 3B). As relações de contato entre esses minerais sugerem a seguinte ordem de formação para essa paragênese tardia: goerceixita $\rightarrow$ monazita $\rightarrow$ barita.
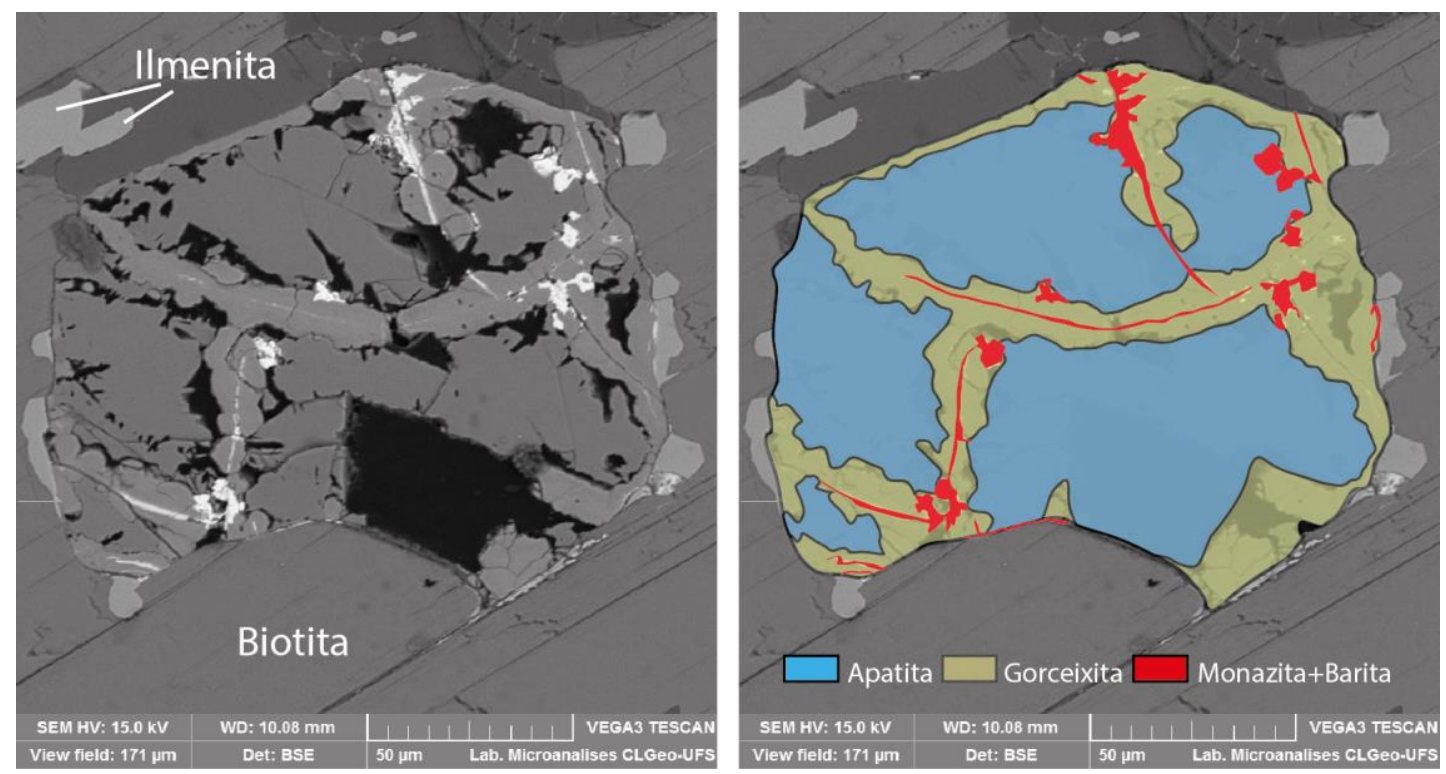

Figura 3: Imagem em BSE de cristal de apatita em seção basal incluso em cristal de biotita (A). A gorceixita (cinza claro) ocorre coroando ou em fraturas de cristais de apatita. A imagem a esquema (B) corresponde a um croqui do cristal da imagem A. Os contatos entre a apatita (azul) e gorceixita (amarelo) são irregulares. No interior dos cristais de gorceixita tem-se fraturas preenchidas por cristais de monazita e barita (vermelho).

Os cristais de flúor-apatita ocorrem distribuídos aleatoriamente nos nefelina sienitos entre outros minerais ou como inclusões em minerais precoces (feldspato alcalino e biotita), particularmente em cristais de biotita (Figura 3A). As relações de contato entre os cristais de flúor-apatita e gorceixita são melhores observadas utilizando-se da CL (Figura 4). Nas imagens em CL percebe-se que os contatos entre os cristais de apatita e a gorceixita são muito irregulares, apresentam-se reentrâncias bem marcadas (Figura 4B), sugerindo que a apatita sofreu ação de fluidos (dissolução?) que levam posteriormente a formação da gorceixita. Estes dados adicionamse a favor as descrições da literatura que relatam que a gorceixita cristaliza-se a baixa temperatura, associada a desestabilização da apatita. Os dados disponíveis na literatura [29, 30] indicam que esse processo ocorre a temperaturas inferiores a $200^{\circ} \mathrm{C}$.

A gorceixita é um mineral da Série da Crandallita [1] e cuja fórmula geral é $\mathrm{AB}_{3}\left(\mathrm{PO}_{4}\right)\left(\mathrm{PO}_{3} \mathrm{OH}\right)(\mathrm{OH})_{6}$. A posição $\mathrm{A}$, com coordenação 12, pode ser ocupada por $\mathrm{Ca}^{+2}, \mathrm{Sr}^{2+}$, $\mathrm{Pb}, \mathrm{Ba}^{2+}$, ETR, Na, U, K, Ag, NH, Bi, Th ou ter vacância. A posição B, em coordenação 6 , pode ser ocupada por $\mathrm{Al}^{3+}, \mathrm{Fe}^{3+}, \mathrm{Cu}, \mathrm{Zn}, \mathrm{Ga}$. A classificação dos membros desse grupo é feita de acordo com o cátion dominante na posição A: crandallita $(\mathrm{Ca})$, goyazita $(\mathrm{Sr})$, plumbogummita $(\mathrm{Pb})$, gorceixita (Ba) e florencita (ETR).

Os cálculos da fórmula estrutural dos cristais analisados foram efetuados com base de 10,5 oxigênios para a gorceixita anidra $\mathrm{AB}_{3}\left(\mathrm{XO}_{4}\right)_{2}$ [4], sendo todo o ferro é expresso como $\mathrm{Fe}^{3+}$. Resultados representativos das análises químicas efetuadas nos cristais de gorceixita são apresentados na tabela 1.

O sítio A é ocupado por Ba (0,577-0,751 a.p.f.u.) e, subordinadamente, por Ca $(0,284-0,081$ a.p.f.u.), $\mathrm{La}(0,065-0,036$ a.p.f.u.), $\mathrm{Ce}(0,101-0,040$ a.p.f.u.), $\mathrm{Na}(<0,079$ a.p.f.u.). O somatório dos cátions no sítio A mostram que existe um défice de carga variando de 0,176 a 0,012 (a.p.f.u.), o que tem sido explicado pela literatura [7] como devido a um maior grau de hidratação desse mineral. Os cátions de $\mathrm{Al}$ e $\mathrm{Fe}$ ocupam o sítio $\mathrm{B}, \operatorname{com} 3,023$ a 2,747 a.p.f.u e 0,053 a 0,035 a.p.f.u, 
respectivamente. $\mathrm{O}$ valor total de cátions nos cristais analisados varia de 5,938 a 5,567 (a.p.f.u.) o que permite considerar esses resultados como bons, quando se compara com os resultados disponíveis na literatura $[3,4,7,31]$.
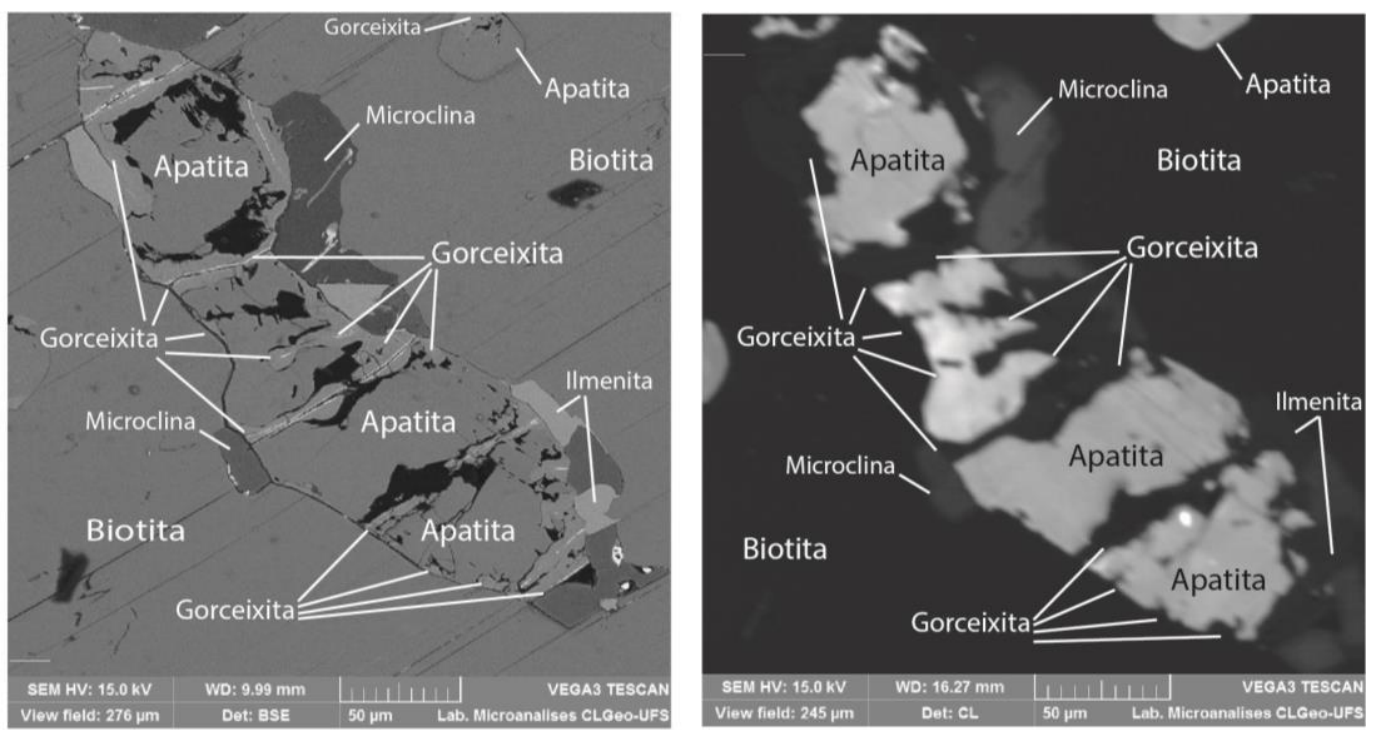

Figura 4: Imagens obtidas de uma mesma área da lâmina PASEBA-2013 e que apresentam as relações texturais entre os cristais de gorceixita e apatita. A imagem da esquerda foi obtida com o detector BSE $e$ a direita por pelo detector $C L$. Os contatos entre a apatita e gorceixita são ressaltados na imagem em $C L$, pois gorceixita vista com a CL fica cinza escuro e a apatita em cinza claro.

A formação de fosfatos aluminosos em condições supergênicas tem sido atribuída à presença de soluções aquosas capazes de transportar o $\mathrm{Al}$, geralmente oriundo da dissolução dos feldspatos ou argilas, $\mathrm{P}$ da apatita e os Elementos Terras Raras de apatita, monazita, allanita [32].

A monazita $\left[(\mathrm{Ce}, \mathrm{La}, \mathrm{Nd}, \mathrm{Th}) \mathrm{PO}_{4}\right]$ pode ter origem ígnea ou supergênica e ocasionalmente pode substituir a apatita [33]. Estes autores propõem que a monazita secundária possa ser formada pela desidratação do rhabdophanio $\left[(\mathrm{La}, \mathrm{Ce}) \mathrm{PO}_{4}\left(\mathrm{H}_{2} \mathrm{O}\right)\right]$. Os trabalhos de [34] indicam que essa síntese se processa a temperaturas inferiores a $50^{\circ} \mathrm{C}$, em condições ácidas (ph variando entre 0,5-5). Dados da literatura indicam que monazita autigênica tem conteúdos mais baixos de Elementos Terras Rarras (ETR) quando comparados àquelas ígneas [7, 35]. Os cristais de monazita analisados apresentam totais dos ETR compreendidos entre 44,9\% e 47\% (Tabela 2), sendo portanto inferiores aos conteúdos totais de ETR, 60\% a 72\%, aquelas magmáticas [35].

\section{CONCLUSÃO}

Identificou-se pela primeira vez cristais de gorceixita em nefelina sienitos do Stock Rio Pardo, na Província Alcalina do Sul do Estado da Bahia. A ocorrência da gorceixita nesses nefelina sienitos é um fato importante, pois revela a presença de atuação de fluidos tardios e de baixa temperatura nessas rochas e está sempre associada a cristais de flúor apatita, sejam eles inclusos em cristais de biotita ou distribuídos aleatoriamente na rocha.

A forma de ocorrência da gorceixita, sempre em fraturas de cristais de apatita, foi interpretada como resultante de uma formação associada a processos supergênicos. Essas feições são consoantes com as descrições existentes na literatura, que associam a formação da gorceixita a perfis de alteração de rochas alcalinas, particularmente aquelas sub-saturadas em óxido de silício. 
Tabela 1. Composições representativas de cristais de gorceixita amostra PASEBA-2013. A análise A corresponde a dados químicos obtidos a partir da composição estequiométrica da gorceixita. A fórmula estrutural foi calculada com base em 10,5 oxigênios. Total de cátions (Tot. Cat.).

\begin{tabular}{|c|c|c|c|c|c|c|c|c|c|c|c|c|c|c|}
\hline & A & 1 & 2 & 3 & 4 & 5 & 6 & 7 & 8 & 9 & 10 & 11 & 12 & 13 \\
\hline $\mathrm{P}_{2} \mathrm{O}_{5}$ & 27,70 & 27,27 & 30,02 & 28,87 & 30,94 & 30,94 & 30,01 & 30,24 & 30,24 & 28,87 & 29,33 & 29,79 & 29,79 & 29,33 \\
\hline $\mathrm{Al}_{2} \mathrm{O}_{3}$ & 29,91 & 30,23 & 29,67 & 30,23 & 30,80 & 30,80 & 30,79 & 30,98 & 30,23 & 29,66 & 30,23 & 31,17 & 30,79 & 31,74 \\
\hline $\mathrm{CaO}$ & & 0,98 & 1,12 & 1,40 & 3,50 & 3,50 & 1,95 & 1,95 & 0,97 & 1,25 & 1,53 & 1,95 & 0,97 & 1,25 \\
\hline $\mathrm{Na}_{2} \mathrm{O}$ & & & & 0,40 & 0,54 & 0,54 & & 0,40 & & & & & & \\
\hline $\mathrm{La}_{2} \mathrm{O}_{3}$ & & 2,23 & & 1,17 & 2,35 & 2,35 & & & & 1,75 & 1,52 & 1,75 & 1,52 & 1,64 \\
\hline $\mathrm{OH}=\mathrm{F}$ & & 1,01 & 0,88 & & & & 0,80 & 0,88 & 0,88 & & & 0,67 & & \\
\hline Total & 87,61 & 88,23 & 86,54 & 87,69 & 92,31 & 90,81 & 87,68 & 89,16 & 86,99 & 88,99 & 87,93 & 90,59 & 88,49 & 87,17 \\
\hline $\mathrm{La}$ & & 0,065 & & 0,036 & 0,066 & 0,066 & & & & 0,053 & 0,046 & 0,050 & 0,045 & 0,049 \\
\hline $\mathrm{Ce}$ & & 0,040 & 0,040 & 0,053 & 0,088 & 0,088 & 0,046 & 0,042 & & 0,101 & 0,063 & 0,066 & 0,069 & 0,072 \\
\hline Sítio A & 1,001 & 0,904 & 0,846 & 1,027 & 1,074 & 1,074 & 0,854 & 0,918 & 0,824 & 0,996 & 0,988 & 0,960 & 0,904 & 0,887 \\
\hline $\mathrm{Al}$ & 3,003 & 2,804 & 2,747 & 2,926 & 2,751 & 2,751 & 2,795 & 2,764 & 2,778 & 2,857 & 2,917 & 2,827 & 2,915 & 3,023 \\
\hline $\mathrm{Fe}^{+3}$ & & 0,042 & & 0,035 & 0,049 & 0,049 & 0,050 & & & 0,053 & & & & \\
\hline Sítio B & 3,003 & 2,846 & 2,747 & 2,962 & 2,800 & 2,800 & 2,845 & 2,764 & 2,778 & 2,909 & 2,917 & 2,827 & 2,915 & 3,023 \\
\hline $\mathrm{P}$ & 1,998 & 1,817 & 1,997 & 2,008 & 1,985 & 1,985 & 1,957 & 1,938 & 1,996 & 1,997 & 2,033 & 1,941 & 2,026 & 2,007 \\
\hline Sítio X & 1,998 & 1,817 & 1,997 & 2,008 & 1,985 & 1,985 & 1,957 & 1,938 & 1,996 & 1,997 & 2,033 & 1,941 & 2,026 & 2,007 \\
\hline Tot.Cat. & 6,002 & 5,567 & 5,590 & 5,996 & 5,859 & 5,859 & 5,656 & 5,620 & 5,599 & 5,903 & 5,938 & 5,728 & 5,844 & 5,917 \\
\hline$F$ & & 0,597 & 0,521 & & & & 0,462 & 0,502 & 0,517 & & & 0,389 & & \\
\hline
\end{tabular}

Tabela 2. Composições representativas em cátions de cristais de apatita (Ap), monazita (Mz), barita (Bar), badaleyíta (Badd), ilmenita (Ilm) expressas em cátions. As duas análises de monazita listadas correspondem aos extremos composicionais determinados no nefelina sienito estudado.

\begin{tabular}{l|r|r|r|r|r|r}
\hline & Ap & \multicolumn{1}{|c|}{ Badd } & \multicolumn{2}{|c|}{ Mz } & \multicolumn{1}{c}{ Ilm } & \multicolumn{1}{c}{ Bar } \\
\hline & & & \multicolumn{2}{|c}{1} & & \\
\hline $\mathrm{O}$ & 36,9 & 23,5 & 26,0 & 31,9 & 32,5 & 24,2 \\
\hline $\mathrm{Ca}$ & 38,6 & & 1,9 & 1,0 & & 0,7 \\
\hline $\mathrm{P}$ & 19 & & 14,7 & 14,1 & & \\
\hline $\mathrm{F}$ & 5 & & & & & \\
\hline $\mathrm{Zr}$ & & 74,5 & & & & \\
\hline $\mathrm{Hf}$ & & 1,1 & & & & \\
\hline $\mathrm{Fe}$ & & & & & 32,0 & \\
\hline $\mathrm{Ti}$ & & & & & 30,1 & \\
\hline $\mathrm{Mn}$ & & & & & 4,5 & \\
\hline $\mathrm{Ta}$ & & & & & 0,5 & \\
\hline $\mathrm{Nb}$ & & & & & 0,5 & \\
\hline $\mathrm{Ce}$ & & & 19,2 & 17,0 & & \\
\hline $\mathrm{Nd}$ & & & 13,3 & 14,3 & & \\
\hline $\mathrm{La}$ & & & 11,1 & 8,1 & & \\
\hline $\mathrm{Y}$ & & & 5,6 & 7,6 & & \\
\hline $\mathrm{Pr}$ & & & 3,4 & 4,2 & & \\
\hline $\mathrm{Sm}$ & & & & 1,3 & & \\
\hline $\mathrm{Al}$ & & & & 1,0 & & \\
\hline $\mathrm{Ba}$ & & & & & & 58,9 \\
\hline $\mathrm{S}$ & & & & & & 14,0 \\
\hline $\mathrm{Tot.} \mathrm{ETR}$ & & & 47,0 & 44,9 & & \\
\hline $\mathrm{T}$ Total & 99,5 & 99,1 & 95,2 & 100,5 & 100,5 & 100,1 \\
\hline
\end{tabular}

A barita é um mineral relativamente comum em fluidos hidrotermais e em perfis pedogênicos. A sua posição nas fraturas da gorceixita, após a formação da monazita indica que a barita é a 
última a se formar. A associação barita e gorceixita sugere que se esteja na transição das condições hipogênica a supergênica e, nesse caso, a gorceixita cristaliza-se a temperaturas inferiores a $60^{\circ}$ C [33].

\section{AGRADECIMENTOS}

Os autores do trabalho externam seus agradecimentos aos órgãos que possibilitaram o desenvolvimento desta pesquisa: Conselho Nacional de Desenvolvimento Científico e Tecnológico $(\mathrm{CNPq})$ e a Fundação de Apoio à Pesquisa e à Inovação Tecnológica do Estado de Sergipe (FAPITEC), processos números: 308059/2014-0 (CNPq-PQ), 308754/2013-1 (CNPqPQ), 473013/2012-4 (CNPq-Universal 2013) e 019.203.02538/2009-7 (PRONEX/FAPITEC/ /CNPq). J.J.A. Santos agradece à Coordenação de Aperfeiçoamento do Pessoal de Nível Superior (CAPES) por sua bolsa de mestrado. Os autores agradecem ao apoio analítico do Laboratório de Microanálise, do Condomínio de Laboratórios Multiusuários das Geociências da Universidade Federal de Sergipe. Agradecem igualmente aos revisores do artigo pelas sugestões e comentários pertinentes.

\section{REFERÊNCIAS BIBLIOGRÁFICAS}

1. Toledo MCM. Mineralogia dos principais fosfatos aluminosos da série da crandallita - uma revisão. Revista do Instituto Geológico, SMA. 1999 Dec;20(1/2):9-17, doi: 10.5935/0100-929X.19990005

2. Rasmussen B. Early-diagenetic REE-phosphate minerals (florencite, gorceixite, crandallite, and xenotime) in marine sandstones: a major sink for oceanic phosphorus. American Jornal of Science. 1996;296(6):601-632.

3. Ferrari VC, Toledo MCM, Atêncio D. Gorceixite from Catalão, Goiás, Brazil: Rietveld Crystal Structure Refinement. Geol. USP Sér. Cient. 2007 Jan;7(2):25-36, doi:http://dx.doi.org/10.5327/ Z1519-874X2007000200002

4. Taylor M, Smith RW, Ahler BA. Gorceixite in topaz greisen assemblages Silverminea area, Missouri. American Mineralogist. 1984 Mar;69:984-986.

5. Kapustin YL. The Mineralogy of Carbonatites (in Russian). Nauka Press, Moscow. 1971;288p.

6. Mckie D. Goyazite and florencite from two African carbonatites. Min. Mag. 1962 Jan;33:281-297.

7. Lottermoser BG. Rare-earth element mineralization with laterite, Western, Australia. Lithos, 1990 Mar;24(2):151-67, doi:10.1016/0024-4937(90)90022-S

8. Ferrari CV. Fosfatos primários e secundários nos perfis de intemperismo sobre os maciços alcalinocarbonatíticos de Juquiá (SP), Anitápolos (SC) e Tapira (MG) [Tese de Doutoramento]. São Paulo (SP): Universidade de São Paulo; 2000. 208 p.

9. Ward CR, Corcoran JF, Saxby JD, Read HW. Occurrence of phosphorus minerals in Australian coal seams. International Journal of Coal Geology. 1996 Jun;30(3):185-210, doi:10.1016/01665162(95)00055-0

10. Bhaskara RA, Cunha ES. Fosfatos dos pegmatitos brasileiros. Recife. Journ. Min. 1968;6:99-121.

11. Pirard C, Hatert F, Hatert F. Alteration sequences of aluminium phosphates from Montebras Pegmatite, Massif Central, France. In: Martins T, Vieira R, editors. Granitic Pegmatites: The State of the Art - International Symposium. 2007 May 6-12, Porto, Portugal. p. 74-75

12. Melo MG. A origem do fosfato nas rochas vulcânicas e vulcanocásticas do Geupo Mata da Corda nas regiões de Patos de Minas e Presidente Olegário, MG [Dissertação]. Ouro Preto (MG): Universidade Federal de Ouro Preto; 2012. 170p.

13. Hussak E. Über die sogenannten "Phosphat-Favas" der diamantführenden Sande Brasiliens. Tschermaks Mineral Petrol Mitt. 1906;25:335-344

14. Rosa MLS, Conceição H, Macambira MJB, Galarza MA, Cunha MP, Menezes RCL, Marinho MM, Cruz Filho BE, Rios DC. Neoproterozoic anorogenic magmatism in the Southern Bahia Alkaline Province of NE Brazil: $\mathrm{U}-\mathrm{Pb}$ and $\mathrm{Pb}-\mathrm{Pb}$ ages of the blue sodalite syenites. Lithos. 2007 Dec;97:8897, doi:10.1016/j.lithos.2006.12.011

15. Menezes RCL, Conceição H, Rosa MLS, Galarza AM, Rios DC, Macambira MJB. O Stock NefelinaSienítico Rio Pardo, Província Alcalina do Sul do Estado da Bahia. Geonomos. 2012 Fev;20(1):1422 .

16. Santos JJA, Rosa MLS, Conceição H. Primeira Ocorrência de Ancilita no Estado da Bahia: Mineral Acessório em Foid Sienitos do Complexo Alcalino Floresta Azul. Scientia Plena. 2014 Out;10(10):1- 
6.

17. Pimenta ACS, Santos JJA, Rosa MLS, Conceição H. Pirocloro no Stock Itajú do Colônia, Sul do Estado da Bahia, Nordeste do Brasil. Scientia Plena. 2015 Jan;11(1):21-26.

18. Santos JJA, Pimenta ACS, Rosa MLS, Conceição H. Primeira ocorrência de zirconolita na Província Alcalina do Sul do Estado da Bahia: intrusão sienítica do Complexo Alcalino Floresta Azul, Bahia, NE Brasil. Scientia Plena. 2015 Set;11(09)1-8, doi: 10.14808/sci.plena.2015.095301

19. Rosa MLS, Conceição H, Macambira MJB, Marinho MM, Menezes RCL, Cunha MP, Rios DC. Magmatismo neoproterozoico no sul do Estado da Bahia, Maciço Sienítico Serra das Araras: geologia, petrográfica idade e geoquimica. Revista Brasileira de Geociências. 2005 Mar;35(1):111-121.

20. Souto PG. Geologia e Petrografia da Área de Potiraguá-Bahia, Brasil [Tese]. São Paulo: Universidade de São Paulo; 1972. 55p.

21. Bordini RM. Geologia do Maciço Anortosítico de Potiraguá, Sul da Bahia [Tese]. Salvador (BA): Inst. de Geociências, Universidade Federal da Bahia; 2003. 171p.

22. Oliveira AEL. Geologia, petrografia, litogeoquímica e idade $\mathrm{Rb}-\mathrm{Sr}$ do Maciço Sienítico Itarantim, Sul do Estado da Bahia [Dissertação]. Salvador (BA): Universidade Federal da Bahia; 2003. 110p.

23. Peixoto AA. Petrologia do Maciço Sienítico Itabuna [Tese]. Salvador (BA): Universidade Federal da Bahia; 2005. 215p.

24. Menezes RCL. Petrogênese da mineralização de sienito azul no Maciço Nefelina-Sienítico Rio Pardo, Sul da Bahia [Dissertação]. Salvador (BA): Universidade Federal da Bahia; 2005. 120p.

25. Bonin B, Giret A. Contrasting roles of rock-forming minerals in alkaline ring complexes. Journal of African Earth Sciences. 1985 Mar;3(1-2):41-49, doi:10.1016/0899-5362(85)90021-1

26. Rosa MLS, Conceição H, Menezes RCL, Macambira MJS, Galarza MA, Oliveira EC, Marinho MM, Cunha MP, Rios DC. Idade U-Pb da mineralização de sodalita-sienito (Azul-Bahia) no Stock Litchfieldítico Itajú do Colônia, sul do Estado da Bahia. Revista Brasileira de Geociências. 2005 Jul;35(3):433-436.

27. Cox KG, Bell JD, Pankhurst RJ. The Interpretation of Igneous Rocks. London: Allen \& Unwin, London; 1979. 445p.

28. Newbury DE Mistakes encountrered during automatic peak identification of minor and trace constituents in eletctron-exicted energy dispersive X-ray microanalysis. 2009; Scanning 31:1-11, doi: $10.1002 /$ sca. 20151

29. Schwab RG, Herold H, Gotz C, Oliveira NP. Compounds of thecrandallite type: Synthesisand properties of pure goyazite, gorceixite and plumbogummite. Neues Jahrbuch Mineralogie Monatshefte. 1990;3(3):113-126.

30. Schwab RG, Herold H, Gotz C, Oliveira NP. Compounds of the crandallitetype: Synthesisand properties of pure Rare Earth Element-phosphates. Neues Jahrbuch Mineralogie Monatshefte. 1990b;6: 241-254.

31. Jelinek AR, Prado M, Bastos Neto AC, Pereira VP, Ronchi LH, Savi CN. Ocorrência de gorceixita e de inclusões sólidas de halita em fluorita da Jazida Nova Fátima: implicações na gênese da mineralização do Distrito Fluorítico de Santa Catarina. Revista Brasileira de Geociências. 2003 Out:33(3):363-370.

32. Marfil R, Iglesia A, Estupiñan J. Origin and nature of the aluminium phosphate-sulfate minerals (APS) associated with uranium mineralization in triassic red-beds (Iberian Range, Spain). J Estudios Geológicos, 69(1. 2013, enero-junio 2013, 21-34, doi:10.3989/egeol.40879.176

33. Mitchell RS, Swanson SM, Crowley JK. Mineralogy of a deeply-weathered perrierite-bearing pegmatite, Bedford County, Virginia. Southeast. Geol. 1976;18:37-47.

34. Hikichi Y, Hukuo KI, Shiokawa J. Synthesis of rare earth orthophosphates. J. Bull. Chem. Soc. Japan. 1978 51:3645-3646.

35. Read D, Cooper DC, McArthur JM. The composition and distribuition of nodular monazite in the Lower Paleozoic rocks of Great Britain. Mineral Magazine. 1987 Jun;51:271-280. 